\title{
Efektivitas Kampanye Ayo Minum untuk Sehat terhadap Kepercayaan Konsumen Le Minerale
}

\author{
Jesslyn Herika Gracia, H.H Daniel Tamburian \\ jesslyn.915160095@stu.untar.ac.id,danielt@fikom.untar.ac.id
}

Fakultas Ilmu Komunikasi Universitas Tarumanagara

\begin{abstract}
In Indonesia, consuming water and exercising are done only by a few people, so various types of diseases and body fatigue attack them. So many public relations or marketing officers of the company think of various ways in order to increase their sales. Therefore, Le Minerale created "Ayo Minum Untuk Sehat" campaign to familiarize people with a healthy life and consume quality mineral water. The purpose of this research was findout "Ayo Minum Untuk Sehat" campaign effectiveness into consumer trust. The main theories used in this research are the campaign theory, consumer trust, and mass communication theory.The method used is a quantitative descriptive method by taking simple random sampling as the simple technique. The population in this study was 7 thousand participants of the campaign of "Ayo Minum Untuk Sehat" with a sample of 99 respondents. After the questionnaire was distributed, an analysis of validity, reliability, normality, correlation coefficient, coefficient of determination, simple regression, and hypothesis testing or t test were carried out. The result of the research reveals that the campaign "Ayo Minum Untuk Sehat" is effective related to consumer trust.
\end{abstract}

Keywords: campaign effectiveness, consumer trust, le minerale

\begin{abstract}
Abstrak
Di Indonesia, mengkonsumsi air putih dan olahraga secara rutin hanya dilakukan oleh sedikit orang, sehingga muncul berbagai jenis penyakit dan rasa tubuh yang cepat lelah. Hadirnya profesi dalam dunia public relations atau marketing membuat perusahaan memikirkan berbagai cara agar dapat mensukseskan perusahaannya. Oleh sebab itu, Le Minerale membuat kampanye Ayo Minum Untuk Sehat untuk membiasakan masyarakat agar hidup sehat dan mengkonsumsi air mineral berkualitas. Tujuan penelitian ini adalah untuk mengetahui efektivitas kampanye Ayo Minum Untuk Sehat terhadap kepercayaan konsumen Le Minerale. Teori utama yang digunakan dalam penelitian ini adalah teori kampanye dan komunikasi massa. Metode yang digunakan adalah metode deskriptif kuantitatif dengan pengambilan teknik sampling berupa simple random sampling. Populasi pada penelitian ini sebanyak 7000 peserta kampanye Ayo Minum Untuk Sehat dengan jumlah sampel sebanyak 99 responden. Setelah kuesioner disebarkan, dilakukan analisis validitas, reliabilitas, normalitas, koefisien korelasi, koefisien determinasi, regresi sederhana, dan uji hipotesis atau uji t. Hasil penelitian mengungkapkan bahwa kampanye Ayo Minum Untuk Sehat efektif secara signifikan terhadap kepercayaan konsumen Le Minerale.
\end{abstract}

Kata Kunci: efektivitas kampanye, kepercayaan konsumen, le minerale

\section{Pendahuluan}

Mengkonsumsi air putih secara rutin dianggap suatu hal yang tidak perlu bagi masyarakat khususnya di Jakarta. Padahal, aktivitas padat yang ada di Jakarta sangat dibutuhkan mengkonsumsi air putih. Seiring perkembangan zaman muncul berbagai tren seperti minuman bobba, es kopi susu gula aren, dan minuman manis lainnya 
dengan alasan minuman manis membuat tubuh kita tercukupi. Hal tersebut membuat tubuh manusia menjadi kekurangan cairan sehingga menimbulkan perasaan cepat lelah, mengantuk dan sakit kepala. Mengkonsumsi air putih disertai olahraga rutin membuat sangat baik untuk tubuh.

Bahkan, penelitian dari Pakar Kesehatan Hidrasi Internasional 2018 mengungkap 500.000.000 masyarakat di dunia jarang mengkonsumsi air putih dalam arti kurang dari 2 botol $600 \mathrm{ml}$ per hari. Hal ini berakibat pada munculnya berbagai penyakit. Seperti yang kita ketahui, orang dewasa harus mengkonsumsi dua liter dalam arti delapan gelas perhari. Dalam penelitian berlangsung ditemukan data bahwa masyarakat Indonesia dalam mengkonsumsi air putih tidak rutin, mereka lebih sering mengkonsumsi minuman manis serta mengandung gula yang tinggi. Anak kecil yang mengkonsumsi minuman yang mengandung gula ditemukan sebanyak dua puluh empat persen, sedangkan generasi millenials atau remaja empat puluh satu persen, sedangkan orang dewasa yang jarang mengkonsumsi minuman yang mengandung gula sebanyak tiga puluh tiga persen. Efek negatif dari mengkonsumsi gula yang berlebihan yaitu dapat mengakibatkan penyakit darah tinggi, obesitas, dan diabetes (https://www.cnnindonesia.com/gaya-hidup/20181108115037-255-344924/kurangminum-air-mineral-berujung-penyakit-kronis diakses pada tanggal 14 Desember 2019 pada pukul 12.06 WIB).

Menyadari minimnya masyarakat dalam mengkonsumsi air mineral dan melakukan cara hidup sehat, salah satu air minum dalam kemasan Le Minerale mengadakan Kampanye Ayo Minum Untuk Sehat. Kampanye yang diadakan oleh Le Minerale ini diharapkan dapat membangun kepercayaan konsumen Le Minerale. Selain itu, Le Minerale ingin meningkatkan cara hidup sehat untuk masyarakat Jakarta.

Menurut Rogers dan Storey (1987) kampanye merupakan rangkaian kegiatan komunikasi dalam perusahaan, organisasi, maupun individu yang terorganisir dengan tujuan agar menciptakan nilai positif perusahaan dari khalayak (Ruslan, 2013)

Ketersediaannya satu pihak dalam penerimaan resiko dari pihak lain dengan harapan bahwa tindakan lain dapat dilakukan untuk pihak yang akan dipercaya sehingga konsumen dapat mempercayai pihak tersebut, hal ini disebut kepercayaan konsumen (Mayer, 1995). Dalam meningkatkan kepercayaan konsumen tersebut, tentu ada kampanye yang efektif. Berdasarkan pemaparan yang ada, maka hipotesis dalam penelitian ini adalah

a. Ho : Tidak terdapat efektivitas kampanye Ayo Minum Untuk Sehat terhadap kepercayaan konsumen Le Minerale

b. Ha : Terdapat efektivitas kampanye Ayo Minum Untuk Sehat terhadap kepercayaan konsumen Le Minerale

Tujuan dari penelitian ini adalah untuk mengetahui efektivitas kampanye Ayo Minum Untuk Sehat terhadap kepercayaan konsumen Le Minerale. 


\section{Metode Penelitian}

\begin{tabular}{|l|l|}
\multicolumn{1}{|c|}{$\begin{array}{c}\text { Efektivitas Kampanye } \\
\text { 1. Monopolization } \\
\text { 2. Canalization } \\
\text { 3. Supplementation } \\
\text { 4. Making personal connection } \\
\text { 5. Creation of new opinions }\end{array}$} & \multicolumn{1}{c}{ (Y) } \\
& 2. Integrity \\
& 3enevolence \\
& 3. Competency \\
\hline
\end{tabular}

Gambar 1: Variabel X dan Variabel Y

Pendekatan yang digunakan dalam penelitian ini adalah deskriptif kuantitatif dengan metode penelitian survei. Metode survei merupakan perolehan fakta-fakta secara penyelidikan dari gejala yang ada untuk pencarian keterangan secara faktual dengan topik sosial, pemerintahan, budaya, politik, maupun keuangan. Penelitian dalam membuat survei dilakukan dalam waktu yang bersamaan terhadap sejumlah orang maupun kelompok secara pribadi atau menggunakan sampel (Nazir, 2011: 56).

Populasi dalam penelitian ini adalah peserta yang mengikuti kampanye Ayo Minum Untuk Sehat. Sedangkan sampel dalam penelitian ini berjumlah 99 responden yang merupakan individu - individu yang mengikuti kampanye Ayo Minum Untuk Sehat 2019. Teknik pengambilan sampel menggunakan metode simple random sampling. Data dikumpulkan dengan membagikan angket atau kuesioner menggunakan teori skala Likert. Data primer yang akan didapat dalam penelitian ini diperoleh berdasarkan hasil angket yang telah disebar oleh penulis. Sedangkan data sekunder diperoleh melalui studi pustaka baik melalui buku, jurnal, ataupun internet. Untuk mengetahui keabsahan data dalam penelitian ini, penulis menggunakan uji validitas, uji normalitas, dan uji reliabilitas. Sedangkan untuk pengolahan data, penulis menggunakan uji koefisien korelasi, koefisien determinasi, regresi linear sederhana, dan uji t.

Tabel 1: Tabel Operasional Variabel

\begin{tabular}{|c|c|c|c|c|}
\hline No & Variabel & Dimensi & Indikator & $\begin{array}{l}\text { Skala } \\
\text { Data }\end{array}$ \\
\hline \multirow[t]{2}{*}{ 1.- } & $\begin{array}{c}\text { Kepercay } \\
\text { aan } \\
\text { Konsume } \\
\text { n }(X)\end{array}$ & $\begin{array}{l}\text { 1. Monopoliz } \\
\text { ation }\end{array}$ & $\begin{array}{ll}\text { a. } & \text { Konsumen melihat } \\
\text { pemberitaan mengenai } \\
\text { kampanye di media lain } \\
\text { b. } \\
\text { Konsumen tidak menemukan } \\
\text { berita yang bertentangan } \\
\text { dengan masalah yang } \\
\text { diangkat oleh Kampanye }\end{array}$ & Nominal \\
\hline & & $\begin{array}{l}\text { 2. Canalizati } \\
\text { on }\end{array}$ & $\begin{array}{llr}\text { a. } & \text { Menunjukkan sikap dan } \\
\text { perilaku yang ada kepada } & \\
\text { konsumen yang belum } \\
\text { mengetahui produk } \\
\text { b. Memberikan pemahaman } \\
\text { kepada konsumen mengenai } \\
\text { tujuan dari kampanye } \\
\text { diadakan }\end{array}$ & Nominal \\
\hline
\end{tabular}




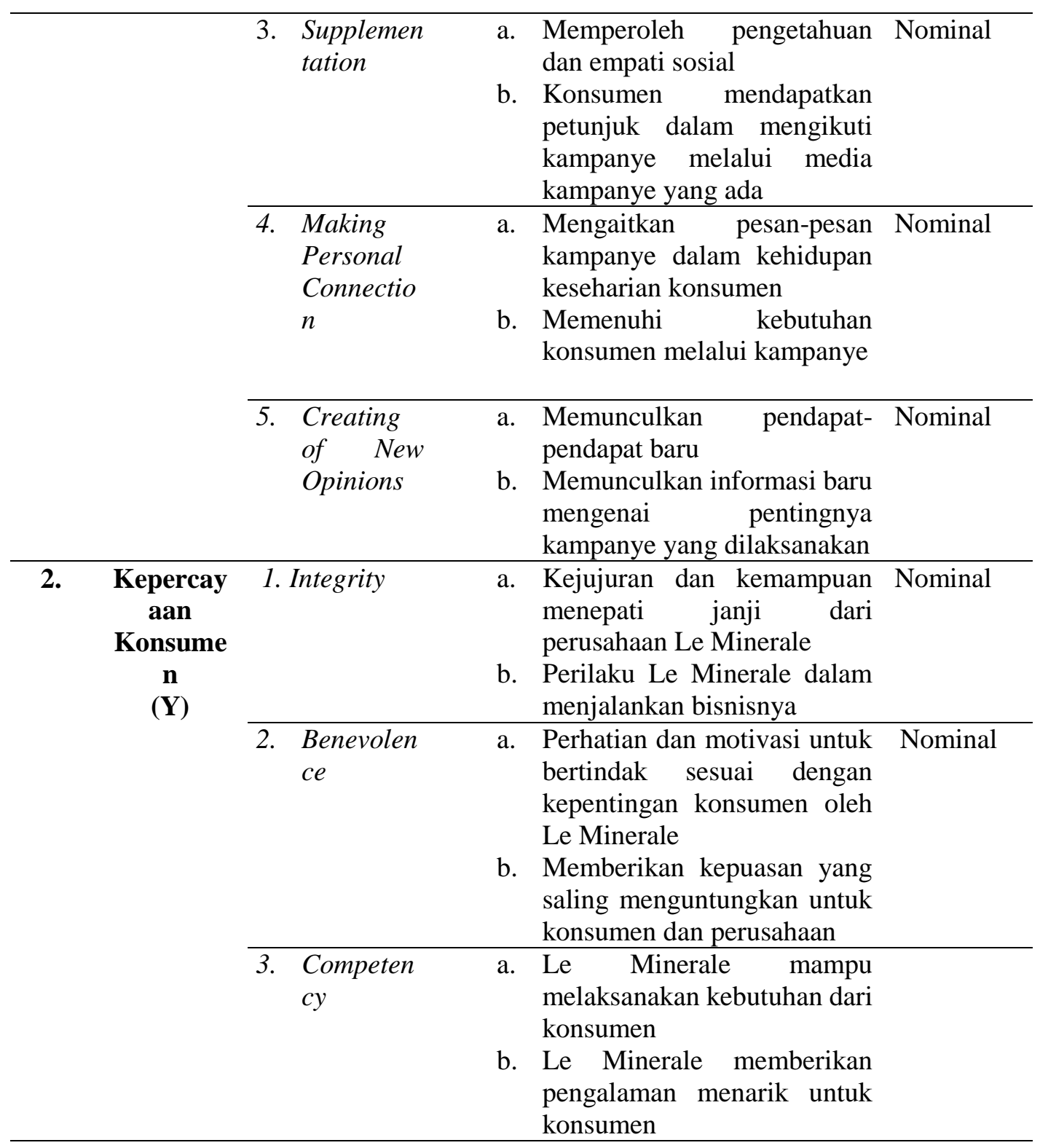

\section{Hasil Temuan dan Diskusi}

Setelah mendapatkan indikator, maka dibuat butir-butir pertanyaan lalu melakukan penyebaran angket melalui Google Forms. Setelah dilakukan penyebaran angket, maka selanjutnya dilakukan pengolahan data untuk uji validitas, reliabilitas, dan normalitas.

Tabel 2. Hasil Analisis Validitas

\begin{tabular}{cccc}
\hline No Soal & $\begin{array}{c}\text { Score Corrected Item } \\
\text { Total }\end{array}$ & Keterangan \\
\hline $\mathbf{X}$ & 0,655 & Valid \\
\cline { 2 - 3 } & P1 & 0,656 & Valid \\
\hline P2 & 0,618 & Valid \\
\hline P3 & 0,624 & Valid \\
\hline P4 & 0,727 & Valid \\
\hline P5 & 0,466 & Valid \\
\hline P6 & & \\
\hline
\end{tabular}




\begin{tabular}{cccc}
\hline & P7 & 0,670 & Valid \\
\hline P8 & 0,780 & Valid \\
\hline P9 & 0,626 & Valid \\
\hline P10 & 0,634 & Valid \\
\hline P11 & 0,614 & Valid \\
\hline Y12 & 0,601 & Valid \\
\hline Y13 & 0,576 & Valid \\
\cline { 2 - 3 } & P14 & 0,704 & Valid \\
\hline P15 & 0,655 & Valid \\
\hline P16 & 0,791 & Valid \\
\hline P17 & 0,745 & Valid \\
\hline P18 & 0,732 & Valid \\
\hline P19 & 0,728 & Valid \\
\hline
\end{tabular}

\section{Uji Reliabilitas X}

Setelah diuji menggunakan SPSS, penulis mendapatkan hasil 0,898. Berdasarkan hasil tersebut, maka pernyataan untuk variabel $\mathrm{X}$ dinyatakan reliabel karena nilai korelasi lebih 0,7, yaitu 0,898 lebih 0,7 .

\section{Uji Reliabilitas Y}

Setelah diuji menggunakan SPSS, penulis mendapatkan hasil 0,898. Berdasarkan hasil tersebut, maka pernyataan untuk variabel Y dinyatakan reliabel karena nilai korelasi harus lebih dari 0,7, yaitu 0,898 lebih besar dari 0,7.

\section{Uji Normalitas}

Setelah diuji menggunakan Uji One Sample Kolmogorov Smirnov yang ada pada aplikasi SPSS, penulis mendapatkan nilai signifikansi sebesar 0,916. Berdasarkan hasil tersebut, maka pernyataan di atas dinyatakan normal karena nilai signifikansi $>0,05$, yaitu $0,916>0,05$. Setelah uji validitas, reliabilitas $X$ dan $Y$, serta uji normalitas dilakukan dan dinyatakan valid, reliabel, dan normal, maka semua pertanyaan tersebut dinyatakan layak untuk disebarkan kepada jumlah responden yang telah ditentukan, dalam hal ini peserta Kampanye Ayo Minum Untuk Sehat yang mengisi kuesioner penulis berdasarkan rumus Slovin yang telah ditetapkan yaitu sebanyak 99 responden.

\section{Analisis Koefisien Korelasi}

Tabel 3 : Hasil Analisis Koefisien Korelasi

\begin{tabular}{llrr}
\hline & & $\begin{array}{c}\text { Efektivitas } \\
\text { Kampanye }\end{array}$ & \multicolumn{1}{c}{$\begin{array}{c}\text { Kepercayaan } \\
\text { Konsumen }\end{array}$} \\
\hline \multirow{3}{*}{ Efektivitas Kampanye } & Pearson Correlation & 1 &, $754^{* *}$ \\
\cline { 2 - 4 } & Sig. (2-tailed) & 99 &, 000 \\
\cline { 2 - 4 } Kepercayaan Konsumen & $\mathrm{N}$ &, $754^{* *}$ & 99 \\
\cline { 2 - 4 } & Pearson Correlation &, 000 & 1 \\
\cline { 2 - 4 } & Sig. (2-tailed) & 99 & 99 \\
\cline { 2 - 4 } & $\mathrm{N}$ & & \\
\hline${ }^{* *}$. Correlation is significant at the 0.01 level (2-tailed). & \\
& Sumber : Aplikasi SPSS & & \\
& &
\end{tabular}


Setelah dilakukan analisis koefisien korelasi, penulis mendapatkan hasil bahwa koefisien korelasi dari variabel X dan Y dalam penelitian ini adalah sebesar 0,754. Hal ini menunjukkan bahwa hubungan efektivitas kampanye $(\mathrm{X})$ memiliki korelasi yang cukup kuat terhadap kepercayaan konsumen (Y).

\section{Analisis Koefisien Determinasi}

Tabel 4. Hasil Analisis Koefisien Determinasi

Model Summary

\begin{tabular}{|l|r|r|r|r|}
\hline Model & $\mathrm{R}$ & $\mathrm{R}$ Square & $\begin{array}{c}\text { Adjusted } \mathrm{R} \\
\text { Square }\end{array}$ & $\begin{array}{c}\text { Std. Error of the } \\
\text { Estimate }\end{array}$ \\
\hline 1 &, $754^{\mathrm{a}}$ &, 568 &, 564 & 2,451 \\
\hline
\end{tabular}

a. Predictors: (Constant), Efektivitas Kampanye

Setelah dilakukan analisis koefisien determinasi, penulis mendapatkan hasil $\mathrm{R}$ Square sebesar 0,568. Hal ini menyatakan bahwa variabel $\mathrm{X}$ dapat menjelaskan terhadap variabel Y sebanyak 56,8\%, sedangkan sisanya dipengaruhi oleh variabel lain.

\section{Analisis Regresi Linear Sederhana}

Tabel 5. Hasil Analisis Regresi Linear Sederhana Coefficients $^{\mathrm{a}}$

\begin{tabular}{|c|c|c|c|c|c|}
\hline \multirow[b]{2}{*}{ Model } & \multicolumn{2}{|c|}{$\begin{array}{c}\text { Unstandardized } \\
\text { Coefficients }\end{array}$} & \multirow{2}{*}{$\begin{array}{c}\begin{array}{c}\text { Standardized } \\
\text { Coefficients }\end{array} \\
\text { Beta }\end{array}$} & \multirow[b]{2}{*}{$\mathrm{t}$} & \multirow[b]{2}{*}{ Sig. } \\
\hline & B & $\begin{array}{l}\text { Std. } \\
\text { Error }\end{array}$ & & & \\
\hline 1 (Constant) & 12,078 & 1,720 & & 7,021 & , 000 \\
\hline $\begin{array}{l}\text { Efektivitas } \\
\text { Kampanye }\end{array}$ & 379 & ,034 & ,754 & $\begin{array}{r}11,29 \\
9\end{array}$ & , 000 \\
\hline
\end{tabular}

a. Dependent Variable: Kepercayaan Konsumen

$$
\mathrm{Y}=\mathrm{a}+\mathrm{bX}
$$

$$
\mathrm{Y}=12,078+0,379 \mathrm{X}
$$

Berdasarkan persamaan tersebut, dapat disimpulkan bahwa konstanta sebesar 12,078 mengandung arti bahwa nilai konsisten variabel kepuasan adalah sebesar 12,078. Sedangkan koefisien regresi X sebesar 0,379 yang menyatakan bahwa setiap penambahan $1 \%$ nilai efektivitas kampanye, maka nilai kepercayaan konsumen bertambah sebesar 12,078. Koefisien regresi tersebut bernilai positif, sehingga dapat diartikan bahwa arah pengaruh variabel $\mathrm{X}$ terhadap $\mathrm{Y}$ adalah positif. Hal ini dapat disimpulkan bahwa semakin banyak event dan kampanye semakin efektif maka kepercayaan konsumen akan turut meningkat.

\section{Uji T}

Tabel 6 : Hasil Uji T ANOVAa

\begin{tabular}{|rl|r|r|r|r|r|}
\hline Model & & \multicolumn{1}{c|}{$\begin{array}{c}\text { Sum of } \\
\text { Squares }\end{array}$} & df & Mean Square & F & Sig. \\
\hline \multirow{2}{*}{1} & Regression & 766,737 & 1 & 766,737 & 127,667 &, $000^{\mathrm{b}}$ \\
& Residual & 582,556 & 97 & 6,006 & & \\
& Total & 1349,293 & 98 & & & \\
\hline
\end{tabular}

a. Dependent Variable: Kepercayaan Konsumen b. Predictors: (Constant), Efektivitas Kampanye 
Berdasarkan hasil perhitungan ANOVA di atas, dapat dilihat nilai Sig. Sebesar 0,000 yang berarti apabila sig $<0,05$ maka Ha diterima. Berarti hasil tersebut dapat disimpulkan bahwa variabel $\mathrm{X}$ berpengaruh secara signifikan terhadap variabel $\mathrm{Y}$ (efektivitas kampanye memiliki hubungan terhadap kepercayaan konsumen). Berdasarkan hasil rekapitulasi variabel X (efektivitas kampanye), dimensi tertinggi ada pada dimensi canalization dan monopolization.

\section{Kesimpulan}

Berdasarkan pemaparan dan hasil penelitian pada bab sebelumnya, maka dapat disimpulkan bahwa kampanye Ayo Minum Untuk Sehat efektif secara signifikan kepercayaan konsumen. Dengan temuan efektivitas kampanye yang berkaitan dengan sebagai 2 (dua) dimensi tertinggi dari total 5 (lima) dimensi efektivitas kampanye Ayo Minum Untuk Sehat. Kampanye Ayo Minum Untuk Sehat dinyatakan efektif terhadap kepercayaan konsumen. Berdasarkan hasil tersebut maka dapat disimpulkan juga bahwa Ha diterima dan Ho ditolak, serta penelitian ini juga mendukung konsep teori kampanye yang membahas tentang efektivitas kampanye dan jenis-jenis kampanye.

\section{Ucapan Terima Kasih}

Penulis mengucapkan terima kasih kepada orang tua, saudara, pasangan, kerabat, teman-teman Fakultas Ilmu Komunikasi 2016 dan responden yang telah memberikan dukungan dan bantuannya kepada penulis. Tak lupa juga ucapan terima kasih kepada perusahaan Le Minerale yang telah mengadakan kampanye sehingga terlaksananya penelitian skripsi ini.

\section{Daftar Pustaka}

Effendi, Masri dan Sofian, Sisingamaribun. (2011). Metode Penelitian Survei. Jakarta: CV Haji Masagung

Effendy, Onong Uchjana. (2015). Ilmu, Komunikasi Teori dan Praktek Komunikasi. Bandung: PT. Citra Aditia Bakti

Ruslan, Rosady. (2013). Kiat dan Strategi Kampanye PR. Jakarta: PT Rajagrafindo Persada

Venus, Antar. (2009). Manajemen Kampanye Panduan Teoritis dan Praktis Dalam Mengefektifkan Kampanye Komunikasi Edisi Revisi. Bandung: PT. Remaja Rosdakarya Offset

Firdayanto, Restika. (2012). 13 Oktober 2019. Persepsi Risiko Melakukan ECommerce Dengan Kepercayaan Konsumen Dalam Membeli Produk Fashion Online. Journal of Social and Industrial Psychology, 1, 1-7

Janne \& Widayatmoko. (2014). Representasi Kampanye Politik Dalam Game (Analisis Semiotik Dalam Game Jokowi Go! Dan Game Prabowo The Asian Tiger). Jurnal Komunikasi, 7,1, 98-107

CNN Indonesia. (2018). 17 September 2019. Kurang Minum Air Mineral Berujung Penyakit Kronis. https://www.cnnindonesia.com/gayahidup/20181108115037-255-344924/kurang-minum-air-mineral-berujungpenyakit-kronis 